\title{
The interaction between training and change in South African organisations
}

\author{
Miemie Struwig \& Elroy Smith* \\ Department of Business Management, Vista University. Private Bag X613, Port Elizabeth, 6000 South Africa
}

\author{
Danie Venter \\ Institute for Statistical Consultation \& Methodology, University of Port Elizabeth, P.O. Box 600, Port Elizabeth, 6000 South Africa
}

Received May 2000

\begin{abstract}
This article outlines the results of a study which investigates the interaction between training and change in South African organisations. A literature study provides a theoretical foundation which explains the nature of the interaction between training and change in the organisation. An empirical survey was conducted, using a self-administered questionnaire which was sent to 365 training practitioners to test six null-hypotheses. To prove the stated hypotheses, specific statistical methods, such as analysis of variance and correlation coefficients, are used. The results showed highly significant relationships between training and organisational change variables (one of the null-hypotheses was rejected). The results indicated that management should use training to facilitate change in the organisation. This, however, requires a shift in emphasis regarding the traditional role of training in the organisation. Training should be placed at the centre of human resources practices and the strategic plans of the organisation.

* Author to whom correspondence should be addressed.
\end{abstract}

\section{Introduction}

The accelerating rate of change is producing a business world in which customary managerial habits in organisations are becoming increasingly inadequate. In the light of worldwide changes, organisations will be required to undergo major, strategic reorientations (Tichy, 1983: 3). Dawson (1994: 176) asserts that 'training can be used as a vehicle for informing employees of the nature, consequences and opportunities afforded by change'. Human \& Horwitz (1992: 96) concur that developing human potential through training is regarded as a feature considered appropriate in organisations which cope well with change. Mulder, Nijhof \& Brinkerhoff (1995: 1) also state that for organisations to continue their existence in the future, they require constant adaptation to new circumstances and that learning plays a crucial role which can be facilitated by organisational training. Harrison (1998: 33) and Kramlinger (1998: 44) contend that trainers need a modemday approach to introduce a new framework for coping with rapid organisational change and that training can play a pivotal role in helping to shape and communicate change messages.

Price (1997: 334), however, asserts that because of organisational change, the traditional role of training has become obsolete. Training cannot only be used to improve knowledge and skills. A change in emphasis is required in which training is placed at the centre of strategic human resources programmes. Bolt, Bures \& Banks (1985: 62) emphasise the fact that training and development activities, aimed at changing managerial behaviour, are not a luxury, but a necessity.

\section{A theoretical perspective of the interaction between training and change in the organisation}

In analysing the literature on change management, three topics continually came to the forefront: organisational development (see for example Larwood, 1984: 450 and Robbins, 1996: 736), the learning organisation (Dawson, 1992: 209 and Hendry, Johnson \& Newton, 1994: 230) and transformational leadership (Bowditch \& Buono, 1994: 235 and Hersey, Blanchard \& Johnson, 1996: 521). It could therefore be said, and for the purpose of this study, that organisational development, the learning organisation and transformational leadership, form the architecture or building blocks of the interaction between training and change. These three aspects would therefore constitute the change variables that are used in the study. An in-depth discussion of these topics, however, falls beyond the scope of this article. A typical slogan of the changing organisation can be:

'Training for transformation through organisational development, in a learning organisation, by means of transformational leadership'.

Regarding the role of training in organisational development, Brewer (1996: 35) is of the opinion that training can be used as a planned managerial programme of individual and organisational growth. Effective change processes need to consider both the forces within the individual and the organisational situation surrounding the individual. Training programmes, utilising organisational development interventions, need to maximise the effectiveness of organisational training activities. Aders \& Gill (1996: 19), however, concur that the role of training in organisational development is not effective in many organisations. O'Connor contends by postulating that trainers should rewrite their job description

'to become the eyes and ears of senior management by identifying critical gaps in business leadership and technical competencies and to fill those gaps with training' (1995: 26).

Training must become more intimately involved with every developmental aspect of the organisation. The need to prove 
the value of training in organisational development initiatives became more critical.

The role of training in the learning organisation is highlighted by Greenberg \& Baron (1997: 92), who argue that training is a systematic approach to incorporating learning in the organisation. Training can be used to prepare employees to meet the challenges and changes in the workplace and to upgrade and refine skills. The best training programmes often use many different approaches, thereby assuring that several different learning principles may be incorporated into training (Bencivenga, 1995: 69). Dobson \& Tosh (1998: 66) are proposing a focus on training in the learning organisation that ensures that business objectives are cascaded into departmental objectives and then ultimately transformed into training objectives. Although Solomon states that an organisation never becomes a learning organisation because by definition it means always evolving, always being in flux and always learning,

'organisational learning provides an incredible opportunity for people to break past the limits of training and move further into the organisation; the learning organisation requires organisational learning in addition to traditional training' (1994: 56).

Mabey \& Salaman (1995:320) advocate that one of the elements of the learning organisation profile is training programmes which are designed to support the change strategies and values held by top management. If learning is a priority, training programmes should be designed to maximise the balance between learning and doing.

According to Jones \& Mann (1992: 207), training should contribute to the development of the innovative capacity of the learning organisation. Changing times are forcing trainers to reconsider their role in the organisation. Initially, training within organisations was largely focussed on specific, welldefined skills which employees needed to improve job performance. Although this type of training remains important in the learning organisation, additional types of training are needed, to empower employees and to seek greater participation from them. In the learning organisation, where employees are expected to invent their own procedures and are empowered to try new ways of functioning, the 'old' training technology seems inappropriate.

The role of training in transformational leadership is emphasised by Bass (1990: 27) who postulates that 'transformational leadership can be learned and it can and should be the subject of management training and development'. Conger \& Kanungo (1988: 312) agree that leadership training provides the individual with an awareness of the nature and dynamics of leadership and with the behaviour involved in it. Through training, the individual discovers his own standing with regard to this behaviour and, thereby, the potential for developing leadership qualities. Training further builds the requisite skills for fulfilling leadership roles (Kuchinke, 1999: 16). This implies that for transformational leadership to be effective, the training programme needs to take into account the social influences on trainees and their disposition. It is important, however, that the elements of transformational influences are identified in clear terms, in order to facilitate training of transformational leaders (Auteri, 1994: 78). This opinion is also held by Yukl (1994: 453) who alleges that training is the most widely used approach for improving leadership in organisations. Various training programmes can be designed to increase skills relevant to managerial effectiveness and advancement, and conceptual and interpersonal skills.

Both Dawson (1994: 64) and Lievegoed (1991: 42) concur that increasing emphasis is being placed on the need for continuous training to support change. Lakhani (1996: II) stresses that training is the seed which will help the organisation to grow, but, at the same time, attention needs to be given to the organisation's systems and values and the distribution of power. Human (1991: 17) also argues that the training of managers is crucial in a changing South A frica. Management training, like other strategic issues, needs to be managed in a volatile and constantly changing context. There is a need to design organisations which promote and enhance learning in order to adapt to changing environments. Figure 1 illustrates the relationship between strategic choice and environmental determinants in organisational adaptation.

\begin{tabular}{|c|c|c|}
\hline \multirow{3}{*}{$\begin{array}{l}\text { Strategic } \\
\text { Choice }\end{array}$} & \multicolumn{2}{|c|}{ igh } \\
\hline & \begin{tabular}{l}
\multicolumn{1}{c}{3} \\
Strategic choice \\
Adaptation by design
\end{tabular} & \begin{tabular}{l}
\multicolumn{1}{c}{2} \\
Differentiated choice \\
Adaptation within constraints
\end{tabular} \\
\hline & \begin{tabular}{l}
\multicolumn{1}{c}{4} \\
Undifferentiated choice \\
Adaptation by chance
\end{tabular} & $\begin{array}{l}1 \\
\text { Minimum choice } \\
\text { Adaptation or selection is out }\end{array}$ \\
\hline
\end{tabular}

Figure 1 Relationship between strategic choice and environmental determinants in organisational adaptation (Source: Jones \& Mann, 1992: 45)

Organisations in quadrant one of Figure 1 are exposed to strong environmental pressures and have few available strategic choices. The role of training is primarily for survival. Organisations in quadrant two experience powerful external constraints, characterised by differentiated strategic choice. As strategic choices are limited in scope by external constraints, training does not have a fully developmental role. This results in a hybrid training role - training for improvement. Organisations dealing with quadrant three situations have few external constraints and freedom of strategic choice. The tendency is to move into areas which imply that goal-directed change is a strong feature. The role of training can be viewed as facilitating the prospecting of new activities hence training for development. Quadrant four organisations are characterised by few strategic choices and external pressures. Training on organisational level seems to be directionless - random training (Jones \& Mann, 1992: 48-49).

According to Thompson \& Mabey (1994: 218) there are two ways in which training (a component of human resources development) can influence the management of organisational change. The first role is to respond to externally driven changes at organisational level (shifts in strategic action). The second role is an internal one - developing and shaping the appropriate competencies, practices and attitudes which will assist the organisation to deliver its products and services. 


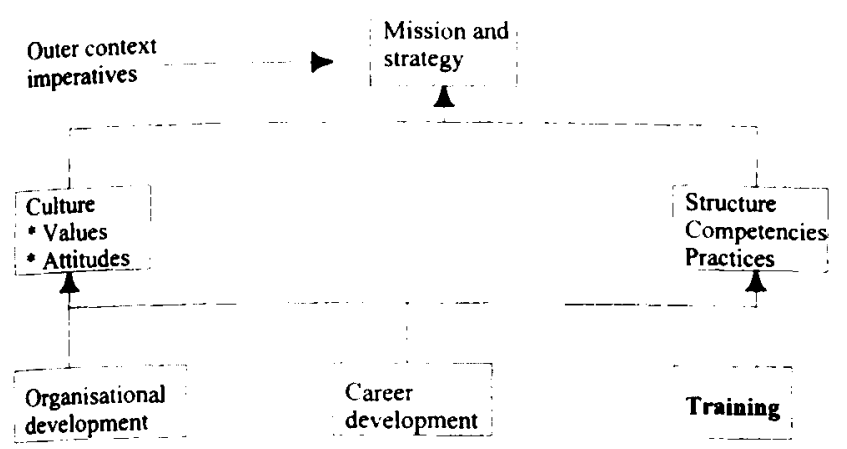

Figure 2 Role of training in managing strategic change (Source adapted from Thompson \& Mabey. 1994: 219)

This dual role of training in managing organisational change is depicted in Figure 2.

Figure 2 shows that the stimulus for change comes from the external environment. The development areas can be viewed as a set of key leverage points in bringing about effective organisational change (of which training is one). Strategic changes need to be anticipated and then interpreted in terms of the necessary now skills and attitudes. Based on this is the design and implementation of appropriate development activities - hence organisational and career development and training. Training initiatives are ultimately linked to the mission of the organisation.

Bowman \& Jarrett (1996: 220) and Thompson (1995: 172) also indicate the use of training as a strategy to facilitate the transition of change. Educating and training people for change beforehand can assist in understanding why the change is necessary. For training to serve as a vehicle for change, change agents must ensure that training is used for the correct purposes. The crucial role of training in the stage of planning the proposed change is emphasised by Burnes (1996: 332). Training is the key element in any change project. The result of training can be the development of new skills, which people are left with the ability to pursue continuous improvement or that they are made aware of the need for change.

Besides the key role of training in planning the change, Brill \& Worth (1997: 62) indicate the role of training in initiating the change process. Through a seminar or workshop, people can examine personal needs, levels of morale and leadership styles. This new insight and perspective can help people to disconnect from old habits and to open up to initiating change in the organisation. According to Kanter, Stein \& Jick (1992: 510), the use of training during the implementation of change is also important. This means that people need to be reoriented, redirected or engaged in new activities which require new knowledge, motivation or skills. Major changes involve many new skills. A change in behaviour patterns and the work environment can both benefit from training programmes. Tobin (1993: 198), on the other hand, advocates the creation of a virtual training organisation and states that the 'traditional training organisation', if it is to assist with organisational transformation, needs to transform itself. The traditional training organisation focuses on the development of individual skills, does not participate in the organisation's planning efforts and is not a change agent.
Training must therefore not only be seen as a functional area in the organisation, but needs to possess the capabilities necessary to help transform the organisation.

\section{Objectives and hypotheses}

The main objective of this article is to investigate the interactive relationship between training and change in the organisation. A theoretical and empirical study will highlight the critical relationship between training and organisational change. It is envisaged to provide guidelines for using training as a vehicle to bring about organisational change. In order to investigate the relationship between training and change variables, various null hypotheses are tested. The null hypotheses tested in this study, are the following:

$\mathrm{H} 0_{1}$ The number of employees (size of organisation) is not related to the role of training in managing organisational change.

$\mathrm{HO}_{2}$ There is no relationship between an organisation which has a fully developed training department and the role of training in managing organisational change.

$\mathrm{HO}_{3}$ There is no relationship between the environment in which an organisation operates and the role of training in managing organisational change.

$\mathrm{HO}_{4}$ There is no relationship between the role of training in managing organisational change and organisational development.

$\mathrm{HO}_{3}$ There is no relationship between the role of training in managing organisational change and the learning organisation.

$\mathrm{H}_{6}$ There is no relationship between the role of training in managing organisational change and transformational leadership.

The null-hypotheses, $\mathrm{HO}_{1}$ to $\mathrm{HO}_{3}$, test the relationship between the role of training in managing organisational change and classification data. $\mathrm{HO}_{4}$ to $\mathrm{HO}_{6}$ investigates the relationship between the change variables (organisational development, learning organisation and transformational leadership) and training variables. The research hypotheses, $\mathrm{H}_{1}$ to $\mathrm{H}_{6}$, can be stated as the exact opposite of the above null hypotheses, indicating that there are relationships between the variables.

\section{Research methodology}

To investigate the role of training in managing organisational change, an empirical study was undertaken.

\section{Sampling procedure}

For the purpose of this research project, the target population was chosen from South African organisations. The main aim of the study is to investigate the facilitating role of training in organisational change. All organisations with a training department or section, headed by a training practitioner or director, could therefore be regarded as the target population. The sample selected for this study was drawn by the South African Board for Personnel Practices (SABPP), including all registered training practitioners.

The ideal would have been to include all training practitioners in South Africa, but such a data base was not available. All registered members who act as training specialists were 
therefore included in the sample. It was felt that these training specialists would be able to provide an objective and expert opinion with regard to the facilitating role of training in change, because they are involved with training in South African organisations. The sample selected for this study consists of 374 training practitioners registered with the SABPP. Nine training practitioners from abroad were excluded from the sample, due to the fact that only South African organisations are to be included. It was felt that conditions in these organisations abroad and the perceptions of these people may be different from that of their South African counterparts. The total sample size is therefore 365 .

\section{Design of the questionnaire}

A questionnaire consisting of three sections is used. A fivepoint Likert-type scale is mainly used in Section A (organisational change variables) and Section B (training variables) of the questionnaire. Section $C$ (classification data) of the questionnaire consists of close-ended questions, using a nominal scale.

\section{Pilot study}

Due to the fact that the questionnaire had never been used before in any research project, a pilot study, including 40 local organisations, was conducted. Wherever possible, it was issued to human resources' managers and training specialists to complete. The questionnaire was also given to academics in the field of management, training, industrial psychology and statistics in order to identify any problem areas and to obtain suggestions. After processing and analysing the data obtained, the questionnaire was refined by making a few minor changes to the wording and the sequence of the questions.

\section{Data collection}

A total of 365 covering letters, questionnaires and return-paid envelopes were posted to the sample group. A reminder postcard was sent a week later to address the problem of low response rates associated with mail surveys.

\section{Data processing and analysis}

Questionnaires which were received from respondents were inspected, edited, coded and transferred for storage. The purpose is to ensure that the data is: accurate, consistent with other information, uniformly entered, completed and arranged to facilitate coding. The coding of questionnaires was carried out by the researcher in conjunction with the statistician responsible for assisting with the analysis of data.
All questionnaires received from respondents were given a reference number $(\mathrm{Q} 1-\mathrm{Q} 182)$ and the receipt date was noted The response rate of this survey is $54.25 \%$ (received 198 questionnaires out of a possible 365 ). The effective response rate (usable questionnaires) is $49.86 \%$ or 182 responses. The following are examples of the techniques used during the data analysis stage of the research project: descriptive statistics, factor analysis, reliability of measuring scales, analysis of variance and correlation coefficients.

The demographic profile of respondents (classification data) is shown in Table 1.

\section{Survey results \\ Descriptive statistics}

Section B of the questionnaire analyses the nature and extent of training in the organisation, with specific reference to the role of training in managing organisational change. All mean values lie between point three (neutral) and four (agree slightly) on the scale. The standard deviation scores indicate no large deviation between the values of these variables (highest standard deviation is 1.15). Figure 3 illustrates the frequency distribution results.

Figure 3 reveals that $18 \%$ of the respondents disagree with the statements regarding the role of training in managing organisational change. Altogether $24 \%$ of respondents neither agree nor disagree with the variables in this part of the questionnaire. The majority of respondents $(58 \%)$ indicate agreement with the aspects regarding the role of training in managing organisational change $(39 \%+19 \%)$. It can be deduced that most of the researched organisations do implement the aspects mentioned and therefore use training as a mechanism to bring about change in the organisation. The distribution can be regarded as negatively skewed and is leptokurtic.

\section{Factor analysis}

The BMDP statistical software package (Programme 4M) was used to perform this factor analysis. Factors were extracted using Principle Component Analysis with Direct Quartimin Oblique rotation to allow for intercorrelations between factors. To confirm that all items load on the single factor and to explain the percentage of variance and to establish the reliability of the various factors, Cronbach's alpha was used in this study (indicating internal consistency). The reliability coefficients of Cronbach's alpha for the various factors are above 0.7 (Cronbach's alpha should be above 0.7 to indicate internal reliability). The following alpha values were calculated: Section A (change variables): organisational development (0.92); learning organisation (0.95); and

Table 1 Descriptive statistics of the classification data

\begin{tabular}{l|llllll}
\hline Variable & \multicolumn{5}{|c}{$\%$ Response } \\
\hline Main activity & Service - & $32 \%$ & Manufacturing - & $25 \%$ & Other - & $43 \%$ \\
Size of organisation & Small - & $20 \%$ & Medium - & $40 \%$ & Large - & $40 \%$ \\
Annual gross revenue & R10mil+ - & $73 \%$ & Rl-R 10 mil - & $22 \%$ & $<\mathrm{R} 1 \mathrm{mil}-$ & $5 \%$ \\
Training department & Yes - & $66 \%$ & No - & $34 \%$ & \\
Post for change agent & Yes - & $30 \%$ & No - & $70 \%$ & \\
Type of environment & Static - & $8 \%$ & Moderate - & $39 \%$ & Dynamic - & $53 \%$ \\
\hline
\end{tabular}




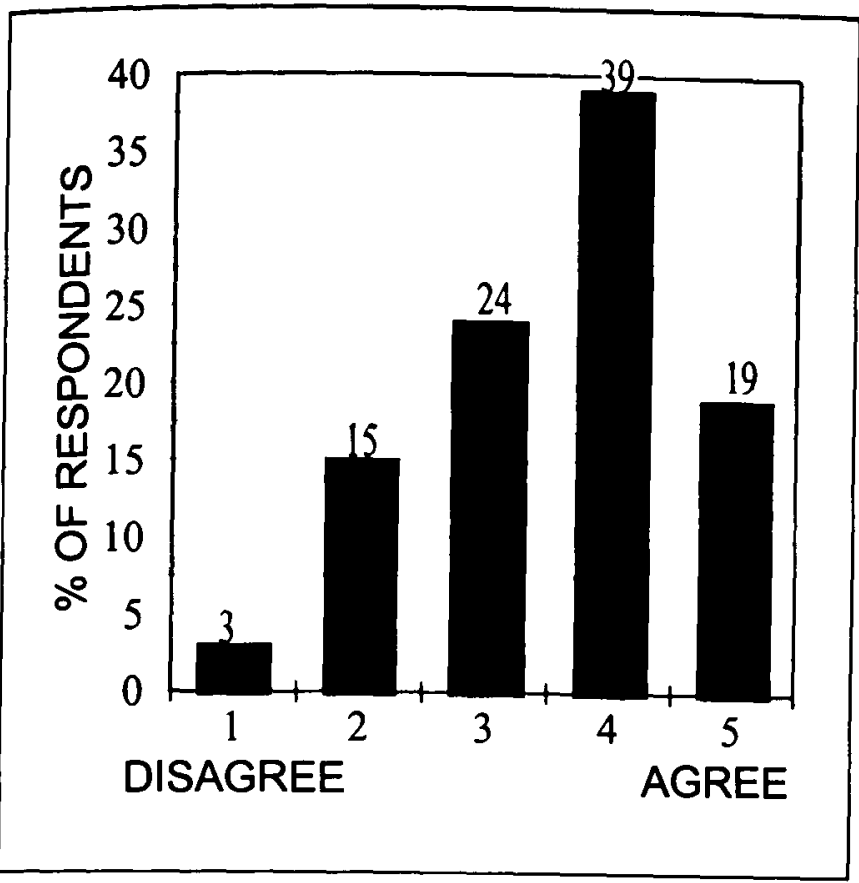

Figure 3 Histogram of the frequency distribution results of Section $B$ of the questionnaire: the role of training in managing organisational change

transformational leadership (0.95) and Section B (training variables): role of training in managing organisational change (0.92). It can therefore be concluded that all factors are internally reliable (Cronbach's alpha $>0.7$ ).

\section{ANOVA}

An analysis of variance was conducted which investigates the relationship between the following variables: Section $A$ and $B$ (dependent variables) and Section $C$ (independent variables) and Section A (dependent variables) and Section B (independent variables). Table 2 shows the results for the first mentioned ANOVA exercise.

The ANOVA results in Table 2 shows that the $F_{2,17}$ value of 1.24 and the P-value of 0.2930 fails to reject the null hy- pothesis, $\mathrm{HO}$. The calculated values fall outside the rejection region $(p>0.05)$ and indicate that there is no relationship between the role of training in managing change and the size of the organisation. The high $F_{1,171}$ statistic of 34.22 and the $P$ value of $0.0000(p<0.01)$ indicates that the calculated values fall within the rejection region and $\mathrm{HO}_{2}$ can therefore be rejected at a significance level of 0.01 . This allows for the acceptance of the research hypothesis $\left(\mathrm{H}_{2}\right)$. There is a relationship between an organisation which has a fully developed training department and the role of training in managing organisational change. The null hypothesis $\mathrm{HO}_{3}$ can be rejected, based on the following analysis: $F_{2,171}$ value of 12.15 and $P$ value of 0.0000 . At an alpha level of 0.01 , it appears that there is a highly significant relationship between the role of training in managing organisational change and the environment in which an organisation operates. The research hypothesis, $\mathrm{H}_{3}$, can therefore be accepted: the environment in which an organisation operates is related to the role of training in managing organisational change. Table 3 indicates the relationship between the independent variables (training) and dependent variables (change).

The $F_{2,179}$ value of 21.02 and the $P$-value of 0.0000 proves that the null hypothesis $\mathrm{H}_{4}$ can be rejected $(\mathrm{p}<0.01)$. There is a relationship between the role of training in managing organisational change and organisational development. The null hypothesis, $\mathrm{HO}_{s}$, falls within the rejection region $(\mathrm{p}<0.01)$ and suggests that $H_{s}$ can be accepted. There is a relationship between the role of training in managing organisational change and the learning organisation. The calculated $F_{2,17 s}$ statistic of 40.97 and the $P$-value of 0.0000 supports the rejection of $\mathrm{HO}_{6}(\mathrm{p}<0.01)$ and the acceptance of $\mathrm{H}_{6}$. There is a relationship between the role of training in managing organisational change and transformational leadership.

\section{Correlations}

Table 4 highlights the correlation matrix of the factors or variables used in the study.

In analysing the $r$-values of the correlation matrix in Table 4 , the critical value used to interpret these $r$-values, at a significance level of 0.01 , is 0.1720 for a sample size of 182 . All the calculated values of $r$ are greater than the critical value $(r$ $>0.1720$ ) which indicates that the relationship between the

Table 2 Analysis of variance results to investigate the relationship between the independent variables (classification data) and the role of training in managing organisational change (B1)

\begin{tabular}{l|ccccc}
\hline Dependent variable (B1) & Sum of squares & Degrees of freedom & Mean square & F-test & P-value \\
\hline Number of employees & 0.92098 & 2 & 0.46049 & 1.24 & 0.2930 \\
Training department & 12.74529 & 1 & 12.74529 & 34.22 & $0.0000^{* *}$ \\
Environment & 9.05278 & 2 & 4.52639 & 12.15 & $0.0000^{* *}$ \\
Error & 63.68698 & 171 & 0.37244 & & \\
\hline
\end{tabular}

** Significance level of $0.01 ; *$ Significance level of 0.05

Table 3 Analysis of variance results to investigate the relationship between training (independent variables) and change (dependent variables)

\begin{tabular}{lccccc}
\hline Dependent variable & Sum of squares & Degrees of freedom & Mean square & F-test & P-value \\
\hline Organisational development & 23.3714 & 2.179 & 11.6857 & 21.02 & $0.0000^{* *}$ \\
Learning organisation & 37.1508 & 2.179 & 18.5754 & 36.29 & $0.0000^{* *}$ \\
Transformational leadership & 41.6017 & 2.179 & 20.8008 & 40.97 & $0.0000^{* *}$ \\
\hline * Significance level of 0.01 & & & & \\
\hline
\end{tabular}


Table 4 Pearson product-moment correlation coefficients: Section $A$ and $B$ of the questionnaire

\begin{tabular}{lcccc}
\hline Variableffactor & A1 & A2 & A3 & B1 \\
\hline A1 & 1.0000 & & & \\
A2 & 0.8620 & 1.0000 & & \\
A3 & 0.7840 & 0.8727 & 1.0000 & \\
B1 & 0.5734 & 0.6733 & 0.7258 & 1.0000 \\
\hline
\end{tabular}

A1 = Organisational development;

A. $=$ The learning organisation;

A3 = Transformational leadership;

B1 = The role of training in managing organisational change

variables is statistically highly significant. It is clearly shown in Table 4 that there is a strong positive correlation or association between the variables.

\section{Conclusion and recommendations}

The majority of respondents agree with the aspects regarding the role of training in managing organisational change. It can be deduced that most of the researched organisations do implement the aspects mentioned and therefore use training as a mechanism to bring about change in the organisation. It is important for management to realise that training can enlarge the capacity of the organisation to adapt to change. Training should be viewed as a systematic approach to incorporate learning in the organisation. Actions should be taken to ensure that training is used to prepare members to meet the challenges and changes in the workplace and to upgrade and refine skills. Training programmes should be designed to support change strategies and learning strategies in the organisation. Increased emphasis should be placed on training programmes which maximise the balance between learning and doing in the organisation. Management should ensure that training contributes to the development of the innovative and learning capacity of the organisation. Increased emphasis should be placed on the role of training in gaining new insight and perspective which can help people to disconnect from old habits and to open up to initiating change in the organisation. Managers should challenge the traditional role of training in the organisation (which focus only on the development of individual skills) by ensuring that training becomes part of the organisation's planning efforts and becomes a change agent in the organisation.

The threat of moving into more open and competitive environments needs to be recognised and participative, developmental and counselling mechanisms should be put into place to support people through a transition. Organisations should view change as an opportunity for individual learning, training and development. Purposeful attempts should be made to use training to manage organisational change, through organisational development, the learning organisation and transformational leadership. The following are specific guidelines and recommendations for using training as a mechanism to bring about change in the organisation:
- The training process in the organisation should be related to the context of the external environment in which the or. ganisation operates.

- Training programmes should enhance the capacity of people to cope with change.

- Training programmes should respond to shifts in strategic actions of the organisation and training initiatives should ultimately be linked to the mission of the organisation.

- Training people for change, prior to it taking place, could assist in understanding why change is necessary.

- Training programmes should be adapted for a specific change situation in the organisation.

- Management should not only view training as a functional area, but one which possesses the necessary capabilities to help transform the organisation.

- Executives should be trained to understand corporate strategy, how to achieve it and to increase awareness of the organisation's competition.

- Training should assist people to become agents for change in the organisation.

- Management should realise that there is a need for a new approach to training which will promote continuous adaptation in the organisation.

The following are the major shortcomings and limitations of this study: although the sample was statistically adequate a slightly larger sample could have been selected; problems were encountered in finding a suitable data base for the study and the role of trade unions as a major stakeholder in bringing about organisational change was ignored. Aspects that could be considered for future research include: the influence of trade unions in shaping change strategies and training policies of an organisation; the development of a South African case study which analyses the aspect of training for change and differences in perceptions of lower level employees and top management regarding aspects of training for change.

The following extract is appropriate with which to conclude this article:

"There seems to be enough evidence that the traditional approaches to managing change are training and development. The issue is what the change agents, particularly human resources' practitioners, should do in order to escalate the learning process in their organisation so as to match the daunting challenges of change ... which require new collective approaches to training and development' (Mbigi \& Maree, 1997: 110 \& 115)

\section{References}

Aders, O.M. \& Gill, S.J. 1996. Building the workforce of the past, Training \& Development, 50(1): 19-21.

Auteri, E. 1994. Upward feedback leads to culture change, Human Resource Magazine, 39(6): 78-82.

Bass, B.M. 1990. From transactional leadership to transformational leadership: learning to share the vision, Organizational Dynamics. 19(3): 19-31.

Bencivenga, D. 1995. Learning organizations evolve in new directions, Human Resource Magazine, 40(10): 69-73.

Bolt, J.F., Bures, A.L. \& Banks, M.C. 1985. Are we meeting the management training challenge?, Training and Development Journal, January: 60-66.

Bowditch, J.L. \& Buono, A.F. 1994. A primer on organizational be- 
haviour. New York: John Wiley \& Sons, Inc.

Bowman, C. \& Jarrett, M.G. 1996. Management in practice: a framework for managing organizational change. Oxford: Butterworth-Heinemann.

Brewer, G. 1996. Is everybody committed?, Sales \& Marketing Management, 148(4): 35.

Brill, P.L. \& Worth, R. 1997. The four levers of corporate change. New York: Amacom.

Bumes, B. 1996. Managing change: a strategic approach to organisational dynamics. London: Pitman Publishing.

Conger, J.A. \& Kanungo, R.N. 1988. Charismatic leadership: the elusive factor in organizational effectiveness. San Francisco: Jossey-Bass Publishers.

Dawson, P. 1994. Organisational change: a processual approach. London: Paul Chapman Publishing, Ltd.

Dawson, S. 1992. Analysing organisations. Hampshire: The MacMillan Press, Ltd.

Dobson, P.C. \& Tosh, M. 1998. Creating a learning organization: training and development in British Steel's Universal Beam Mill, Total Quality Management, 9(4/5): 66-70.

Greenberg, J. \& Baron, R.A. 1997. Behaviour in organizations. New Jersey: Prentice-Hall, Inc

Harrison, R. 1998. Move with the goal posts, People Management, 4(2): 33.

Hendry, J., Johnson, G. \& Newton, J. 1994. Strategic thinking: leadership and the management of change. Chichester: John Wiley \& Sons

Hersey, P., Blanchard, K.H. \& Johnson, D.E. 1996. Management of organizational behaviour. New Jersey: Prentice-Hall, Inc.

Human, L. 1991. Educating and developing mangers for a changing South Africa. Cape Town: Juta \& Company, Ltd.

Human, P. \& Horwitz, F. 1992. On the edge: how South African companies cope with change. Kenwyn: Juta \& Co. Ltd.

Jones, M. \& Mann, P. 1992. Human resource development: international perspectives on development and learning. West Hartford: Kumarian Press, Inc.

Kanter, R.M., Stein, B.A. \& Jick, T.D. 1992. The challenge of organizational change. New York: The Free Press.
Kramlinger, T. 1998. How to deliver a change message, Training \& Development, 58(4): 44-47.

Kuchinke, K.P. 1999. Leadership skills make a difference on the line, IIE Solutions, 31 (3): 16

Lakhani, K. 1996. Changing 'them' versus changing 'us', People Dynamics, 14(2): 11.

Larwood, L. 1984. Organizational behaviour and management. Boston: Kent Publishing Company.

Lievegoed, B. 1991. Managing the developing organisation. Oxford: Basil Blackwell.

Mabey, C. \& Salaman, G. 1995. Strategic human resource management. Oxford: Blackwell Business.

Mbigi, L. \& Maree, J. 1997. The spirit of African transformation management. Randburg: Knowledge Resources, Ltd.

Mulder, M., Nijhof, W.J. \& Brinkerhoff, R.O. 1995. Corporate training for effective performance. Boston: Kluwer Academic Publishers.

O'Connor, V. 1995. Trainers rewrite their job description, Management Review, 84(6): 26-27.

Price, A. 1997. Human resource management in a business context. London: International Thomson Business Press.

Robbins, S.P. 1996. Organizational behavior. New Jersey: PrenticeHall, Inc.

Solomon, C.M. 1994. HR facilitates the learning organization concept, Personnel Journal, 73(11): 56-64.

Thompson, R. 1995. Managing people. Oxford: Butterworth-Heineman.

Thompson, R. \& Mabey, C. 1994. Developing human resources. Oxford: Butterworth.

Tichy, N.M. 1983. Managing strategic change: technical, political and cultural dynamics. New York: John Wiley \& Sons.

Tobin, D.R. 1993. Re-educating the corporation. Essex Junction: Oliver Wight Publications, Inc.

Yukl, G. 1994. Leadership in organizations. New Jersey: PrenticeHall. 